\title{
STUDY OF THE POSITIVITY OF SPONTANEOUS AND DIRECTED DIAGNOSIS OF LEUKOARAIOSIS IN THE ELDERLY BY CRANIAL COMPUTERIZED TOMOGRAPHY, AND ITS CORRELATION WITH COGNITIVE DEFICIT AND CARDIOVASCULAR RISK FACTORS
}

\author{
Mauricio de Miranda Ventura', Antonio Carlos de Paiva Melo², \\ Henrique Carrete Jr3 ${ }^{3}$ Ricardo Vieira Botelho 4
}

\begin{abstract}
Objective: To evaluate the prevalence of leukoaraiosis (LA) and its correlation with vascular risk factors and the cognitive performance of elderly patients. Method: 78 patients were randomly selected and submitted to clinic-laboratorial evaluation for vascular risk factors. Two cognitive tests were performed. All patients were submitted to cranial computerized tomography (CT), which was analyzed in two situations: the spontaneous and the directed way. Results: There was no statistically significant difference between the prevalence of spontaneous and the directed diagnoses of LA ( 20.5 and $18 \%$, respectively). The presence of LA was not significantly correlated with cognitive impairment. Only age was positively associated with LA. Conclusion: Cranial CT is a trustworthy method for the diagnosis of LA. Only age showed a positive association. No clinical implications were found, concerning the cognitive performance of the patients.
\end{abstract}

KEY WORDS: leukoaraiosis, cognition disorders, risk factors.

\begin{abstract}
Estudo da positividade do diagnóstico espontâneo e dirigido da leucoaraiose em idosos pela tomografia computadorizada de crânio e sua correlação com déficits cognitivos e fatores de risco cardiovascular

RESUMO: Objetivo: Avaliar a prevalência da leucoaraiose (LA) em idosos e correlacioná-los com fatores de risco vasculares e seu desempenho cognitivo. Método: 78 pacientes foram selecionados aleatoriamente e submetidos a avaliação clinico-laboratorial para fatores de risco vascular. Dois testes cognitivos foram realizados. Todos os pacientes foram submetidos a tomografia computadorizada (TC) de crânio, que foi analisada em duas situações: de forma espontânea e dirigida. Resultados: Não houve diferença estatisticamente significativa entre as formas de diagnóstico espontâneo e dirigido da LA (20,5 and $18 \%$, respectivamente). Com relação ao desempenho cognitivo, a presença da LA não determinou prejuízo significativo. Somente a idade mostrou associação positiva com a LA. Conclusão: A TC de crânio é um método confiável para o diagnóstico de LA. A idade foi o único fator de risco que mostrou associação positiva. Não houve prejuízo quanto ao desempenho cognitivo.
\end{abstract}

PALAVRAS-CHAVE: leucoaraiose, transtornos cognitivos, fatores de risco.

The cranial computerized tomography (CT) is a diagnostic method which is widely used in the areas of Neurology and Geriatrics. The detection of leukoaraiosis (LA) in the CT of the encephalon is frequent. This term was introduced by Hachinski et al.', who described a radiological alteration characterized by hypoattenuations around the cerebral ventricles in images obtained by $\mathrm{CT}$. With the advent of magnetic resonance (MR), the corresponding detection is the alteration of intensity of the signal (hypersignal) in the acquisition in T2. Due to its greater sensitivity, MR has been considered the best diagnostic method ${ }^{2}$. Nevertheless, Lopez et al. ${ }^{3}$ found stronger clinic-pathological correlation with the $\mathrm{CT}$, specifically concerning the appearance of symptoms of brain-vascular disease in possible sufferers of Alzheimer's disease. CT, due to

Hospital do Servidor Público Estadual "Francisco Morato de Oliveira", São Paulo SP, Brasil: 'Médico do Serviço de Geriatria; Diretor do Serviço de Neurologia; ${ }^{3}$ Médico do Serviço de Radiologia; ${ }^{4}$ Médico do Serviço de Neurocirurgia.

Received 6 June 2007, received in final form 11 September 2007. Accepted 8 October 2007.

Dr. Ricardo Vieira Botelho - Rua Dr. Haberbeck Brandão 68 / 92 - 04027-040 São Paulo SP - Brasil. E-mail: bitbot@uol.com.br 
its lower costs, frequently precedes the MR in the investigations of pathologic processe of the central nervous system (CNS), and it may be the only diagnostic method available for countless populations.

The clinical significance of the LA is uncertain. And, although it is considered part of natural aging associated with brain-vascular risk factors, it could either contribute to the presence of cognitive deficits in healthy people, or to worsen deficits as well as vascular dementia in sufferers of Alzheimer's disease 4 . Nevertheless, the real clinical implications of LA remain unclear.

We have studied the prevalence of LA in an elderly population who showed no evidence of cognitive alterations, the effect of previously directed diagnosis for the research of LA and its prevalence, and we correlated the cognitive deficit with the presence of comorbidities and smoking. Our main objective was to evaluate the prevalence of LA (in studies with $C T$ ) in a population of non-suffers of dementia or of brainvascular diseases. The secondary objectives were: to evaluate differences concerning the prevalence of the diagnosis of LA when radiological study was conducted through directed method (it was required, previously, to the radiologist to check the presence of LA and to classify it) and through spontaneous method; to study and compare the cognitive performance of the patients who were suffers of LA and those who were not; to correlate anthropologic data (age and sex), level of education and the presence of chronicdegenerative diseases with LA.

\section{METHOD}

With the objective to reduce the selection bias, a list of outpatients (who frequented the Ambulatory of Geriatric Service) were generated and a number was attributed to each one. The candidates were than picked up by a closed envelope lottery. Those who did not bear dementia, brainvascular diseases or any other disease which was severe enough to cause cognitive deficit or to prevent them from going through $\mathrm{CT}$, were selected. Patients showing sensorial deficit (auditive and/or visual) were excluded to make sure the results of the cognitive tests would not be affected.

The research project was approved by the Research Ethics Committee of the Instituto de Assistência Médica ao Servidor Público Estadual, and the patients agreed with the terms of postinformed consentiment.

All patients were submitted to general clinical evaluation concerning their cognitive capacity.

The clinic evaluation consisted of medical history, use of medications and physical and neurological exams. We were particulary interested in the presence of the following chronic-degenerative diseases: hypertension (HT), diabetes mellitus (DM), dislipidemy, obesity and smoking. We identified and correlated them with the presence of LA.
The cognitive evaluation was done through Structured Interview for the Diagnosis of Dementia (SIDAM) - validated for the diagnosis of dementia ${ }^{5}$, for the diagnosis of mild cognitive impairment ${ }^{6}$, whose version in Portuguese was validated by Ventura and Bottino ${ }^{7}$ and through the Mini Mental State Exam (MMSE) ${ }^{8}$.

The analysis of CT was done in two moments: in the first phase, a report was issued by the neuroradiologist who did not know the diagnosis of the patient or the objective of the study (spontaneous diagnosis); in the second phase, the neuroradiologist was requested to determine specifically the presence or absence of LA, and, in affirmative case, to quantify the intensity of LA (directed diagnosis), according to the method of van Swieten et al. ${ }^{9}$ (Table 1).

Statistical analysis - The variables were described by means and standard deviation. The difference between the distribution of the spontaneous and the directed tomographic diagnosis was evaluated through test of McNemar $^{10}$. Concerning age, level of education, MMSE and SIDAM, the comparison between the groups with or without LA, according to the two methods used, was done through Mann-Whitney test ${ }^{11}$. For the study of the differences of distribution of qualitative variables (HT; DM; dislipidemy; obesity and smoking) between the groups with and without LA, the exact Fisher test or qui-square test were used. The level of significance was defined as $\mathrm{p} \leq 0.05$. The statistical program used was the Statistic 6.0.

\section{RESULTS}

Initially, the 78 patients were submitted to the protocol of the study, by accomplishing clinical, neurological and cognitive evaluation. Their CTs were

Table 1. Graduation of the lesions of the white substance in the cranial computerized tomography.

\begin{tabular}{ll}
\hline Region to be analysed & $\begin{array}{l}\text { Graduation } \\
\text { of leukoaraiosis }\end{array}$ \\
\hline $\begin{array}{l}\text { White substance around anteri- } \\
\text { or horns of lateral ventricles }\end{array}$ & $\begin{array}{l}\text { Degree o - ( ) } \\
\text { Degree I - ( ) } \\
\text { Degree II- ( ) }\end{array}$ \\
White substance around the posterior & Degree o - ( ) \\
surface of the medial cell and posterior & Degree I - ( ) \\
surface of semi-oval centre & Degree II - ( ) \\
\hline
\end{tabular}

Table 2. Prevalence of chronic-degenerative diseases and their relation with $L A$.

\begin{tabular}{lccc}
\hline & Without LA & With LA & $p$ \\
\hline HT & $38(48.718 \%)$ & $11(14.103 \%)$ & 0.5844 \\
DM & $11(14.103 \%)$ & $3(3.84 \%)$ & $*$ \\
Dislipidemy & $34(43.59 \%)$ & $5(6.4 \%)$ & 0.946 \\
Smoking & $19(24.35 \%)$ & $4(5.128 \%)$ & 0.8934 \\
Obesity & $40(51.28 \%)$ & $10(12.82 \%)$ & 0.8816 \\
\hline
\end{tabular}

*cases number insuficient for analysis. 
Table 3. Prevalence of spontaneous and directed diagnoses of LA.

\begin{tabular}{llll}
\hline Spontaneous diagnosis & Without LA & & 62 patients $(79.5 \%)$ \\
& With LA & 16 patients $(20.5 \%)$ \\
\hline Directed diagnosis & Without LA: 59 patients (75.6\%) & Degree o & 59 patients $(75.6 \%)$ \\
& With LA: 14 patients (18\%) & Degree 1 & 7 patients $(8.9 \%)$ \\
& & Degree 2 & 4 patients $(5.1 \%)$ \\
& Degree 3 & 2 patients $(2.5 \%)$ \\
& Degree 4 & 1 patient $(1.3 \%)$ \\
& & 5 patients $(6.4 \%)$ \\
\hline
\end{tabular}

Table 4. Probability associated (p) to differences in the distribution of LA in relation to age, school level and cognitive performance according to LA's spontaneous diagnoses (Mann-Whitney).

\begin{tabular}{lccc}
\hline Variable & Without LA & With LA & $p$ \\
\hline Age & 73.89 & 79.56 & 0.001 \\
School level & 6.65 & 5.94 & 0.630 \\
MMSE & 25.28 & 23.44 & 0.059 \\
SIDAM & 42.05 & 37.63 & 0.067 \\
\hline
\end{tabular}

submitted to analysis through spontaneous diagnosis. Five patients, or members of their families, declined to take part in the study, and 73 exams, among the initial 78 , were submitted to directed diagnosis.

Patients' average age was 75.1 years (sd: 6.47); $71.8 \%$ (56 patients) were female and $28.2 \%$ (22 patients) were male.

Concerning their educational background, $55.1 \%$ of the patients had low educational level (up to 4 years); $12.8 \%$ had medium educational level ( 4 to 8 years); $32.1 \%$ had a high educational level (more than 8 years).

In relation to the chronic-degenerative diseases: $62.82 \%$ were hypertense; $64.10 \%$ were obese; $50 \%$ had dislipidemy; $29.48 \%$ were tabagist, and $17.94 \%$ had diabetes mellitus. Table 2 shows the prevalence of comorbidies and smoking, as well as the p-value of the association with LA.

The prevalence of LA perceived was $20.5 \%$, according to spontaneous diagnosis, and of $18 \%$, according to directed diagnosis ( $p=0.727$; McNemar). Only in 8 cases the diagnoses were different, depending on the approach used (Table 3). There were no significant differences between the directed and the spontaneous diagnoses. Based on the lack of difference between the spontaneous and directed methods, we used only the former up to discussion.

In Table 4 we observe that: the age of the individuals with LA was significantly higher than that of individuals without LA, according to spontaneous diagnoses $(p=0.01)$; the distribution of patients with and without LA was not different when compared to their level of education $(p=0.630)$; there were differences, close to the level of significance, concerning the cognitive performance of the patients with LA (MMSE: $\mathrm{p}=0.059$; SIDAM: $\mathrm{p}=0.067$ ) (Table 4).

\section{DISCUSSION}

Since its initial description, there has been a lot of discussion in the literature concerning the causes and the clinical correlation of LA. There may even be some confusion relating to previous brain alterations and loss of involutive and nonspecific white substance, which occurs as age advances. There has also been discussion concerning the possibility of the existence of LA only as an incidental radiologic diagnosis (without clinical correspondence), on assymptomatic patients. There are different neurologic findings which may contribute to the presence of periventricular hypodensities: perivascular demielinization and gliosis; dilatation of Virchow-Robin spaces; small gaps; loss of axons and glial cells (predominantly oligodendrocytes); rarefaction of myelin associated with spongiosis; presence of multiple gaps and numerous sclerotic plates. Nevertheless, as mentioned by Hachinski et al. ${ }^{1}$, a simple infiltration of the spinal-brain liquid into the periventricular brain parenchyma would be enough to cause radiologic alteration, typical of LA.

According to directed and spontaneous diagnoses, 18 to $20.5 \%$ of the elderly patients without evident cognitive deficit presented tomographic images of LA. There were no significant differences between the two forms of diagnostic evaluation. The spontaneous diagnosis, done by radiologist without the tendency imposed by the objective of the research must be considered trustworthy.

Patients with LA showed different cognitive performance when compared to those without LA. Although the difference did not reach the defined level of significance, in case we accepted the level of significance of ten per cent $(p=0.10)$, the difference would 
have been determined $(p=0.059$ MMSE and $p=0.067$ SIDAM). It is possible that the test used, with lower power of evaluation (non parametric Mann-Whitney), and the size of the sample have contributed to the final results. Through spontaneous diagnosis, researchers analyzed only the presence or the absence of LA, regardless of its intensity.

The majority of the patients in our sample were diagnosed as having LA of I and II degrees. It is possible that the prevalence of LA of low intensity has contributed for these results, and that suggests that LA of lower level is less intensely correlated with cognitive deficit. The small number of patients with LA of more advanced levels does not allow us to draw any major conclusions. Our study excluded patients with evident cognitive deficit.

As far as sensitivity is concerned, the cranial CT is not the best method for the diagnosis of LA, nor is it the best way to qualify it. Nonetheless, because of the high cost of the MR, the greater availability of the $C T$, the difficulties for realizing the exam with MR in elderly patients, the CT was considered the most available, economic and functional method. It is worth mentioning that Lopez et al. ${ }^{3}$ found more significant clinical-pathological correlation with the $\mathrm{CT}$, specifically concerning the appearance of symptoms of vascular brain disease in probable bearers of Alzheimer's disease.

In the studies about the correlation between LA and cognitive profile, Steingart et al. ${ }^{12}$ studied, prospectively, 105 voluntary normal elderly patients, by $\mathrm{CT}$, psychometric evaluation and neurological exams. In that sample, patients who had LA showed a worse performance in the cognitive tests.

Steingart et al. ${ }^{13}$ evaluated 113 patients through the use of the CT (of the skull), neurological exams and psychometric tests. All patients had dementia syndrome, and $80,5 \%$ of them were diagnosed as having Alzheimer's disease, and 39 were found to have LA. Comparison between these two groups revealed that those patients with LA showed a worse performance in the psychometric tests.

Kluger et al. ${ }^{14}$ have reported the results of their study, according to which 6 elderly patients with lesions of the peri-ventricular white substance in the region of the anterior horn of the lateral ventricle, as their CT (of the skull) revealed, showed sub-clinical deficits in the motor psychometric tests, when compared with other 11 patients who did not present the same lesions. This suggests that theses lesions may affect, primarily, psychomotor activities.
Hogervorst et al..$^{15}$ compared the CT of healthy patients to those of patients with Alzheimer's disease, evaluating the intensity of the LA. The cognitive performance of the two groups, according to MMSE (MESM), did not show any statistically significant difference, as far as the normal patients were concerned, but in relation to patients with Alzheimer's disease, the performance, in the MMSE (MESM), was worse among those with LA.

Smith et al. ${ }^{16}$ studied the influence of LA in cognitive deficits. The CT of 182 patients with brain hemorrhage were analyzed, blindly - as far as the clinic history of the patients was concerned - by radiologists, who then quantified the LA. These patients were accompanied through interviews carried out through the telephone. A positive association was established between cognitive deficits and the intensity of the LA in patients, after an episode of intra-brain hemorrhage. Hachinski et al. ${ }^{1}$ note the positive association between LA and intellectual decay, and discuss its association with Alzheimer's disease, which is justified by the fact that amyloid angiopathy was found to have the same neuropathological characteristics in both diseases.

The studies which compared cognitive performance in the presence of LA, by means of $C T$, got to the conclusion that it may lead to a discrete deficit, with no significant difference. The study carried out by Smith et al. ${ }^{16}$, which showed a positive association with LA, depending on its intensity, evaluated the patients after an episode of severe intra-brain hemorrhage, differently from us who have excluded patients with any sort of brain-vascular problem. Furthermore, differently from our study, there was a post evaluation through telephone interviews about how patients had progressed, and this may have corroborated their findings.

Pantoni and Garcia 4 , in a review article, considered LA as part of normal aging process. Nevertheless, if it is aggravated by brain-vascular risk factors, it could contribute to the presence of discrete cognitive deficits in healthy people, or to worsen cognitive deficits in patients with Alzheimer's disease or with vascular dementia, and, eventually, it could increase the risk of brain-vascular problems.

When comorbidities and chronic disease were taken as risk factors for LA, our study revealed age as the only variable positively associated with LA. This was observed in both diagnoses, spontaneous and directed, and was corroborated by other studies ${ }^{12,13,15,16}$.

Arterial hypertension could be another predisponent factor, although studies which have used CTs are 
not conclusive in relation to this possibility: Steingart et al. ${ }^{12}$, Hogervorst et al. ${ }^{15}$ and Smith et al. ${ }^{16}$ did not find this relationship in their studies, while Steingart et al. ${ }^{13}$ were the only ones to establish it. In our study, regardless of the diagnostic approach used, it was not possible to establish a positive association between LA and arterial hypertension. A possible reason is the fact that patients with brain-vascular diseases were excluded, and patients with more intense LA were a minority in our casuistics, although more than $62 \%$ of the individuals in the research were hypertense. In other studies which have established this association, the presence of brain-vascular disease was an important condition for the inclusion of patients. There are doubts concerning the relevance of other vascular risk factors, and it is not probable that dislipidemy, diabetes mellitus, obesity and smoking play any role in its etiology.

In conclusion, the rate of prevalence of LA in a population who does not have brain-vascular dementia or disease was $\mathbf{2 0 . 5 \%}$. The prevalence of LA did not increase according to the directed nor with the spontaneous mode of research applied. Age was the anthropometric variable which showed the strongest association with the LA. There was an indication of the association of the LA with cognitive deficit, although we have not reached the level of significance determined for this study. Studies with a greater number of individuals, as well as the study of patients with previous cognitive deficit could make this association clearer. No cronic-degenerative diseases, nor smoking, were associated to the presence of LA.

\section{REFERENCES}

1. Hachinski WC, Potter P, Mershey H. Leuko-araiosis. Arch Neurol 1987;44:21-23.

2. Erkinjuntti T, Ketonen L, Sulkava R, Sipponen J, Vuorialho M, Iivanainen M. Do white matter changes on MRI and CT differentiate vascular dementia from Alzheimer's disease? J Neurol Neurosurg Psychiatry 1987;50:37-42.

3. Lopez OL, Becker JT, Jungreis CA, et al. Computed tomograpy - but not magnetic resonance imaging - identified periventricular white-matter lesions predict symptomatic cerebrovascular disease in probable Alzheimer's disease. Arch Neurol 1995;52:659-664.

4. Pantoni L, Garcia JH. The significance of cerebral white matter abnormalities 100 years after Binswanger's report: a review. Stroke 1995; 26:1293-1301.

5. Zaudig M, Mittelhammer J, Hiller W, Pauls A, Thora C. SIDAM: a structured interview for the diagnosis of dementia of the Alzheimer type, multi-infarct dementia and dementia of other etiology according to DSM III R and ICD 10. Psychol Med 1991;21:225-236.

6. Zaudig M. A new sistematic method of measurement and diagnosis of mild cognitive impairment and dementia accorging to DSM III R and ICD 10. Int Psychogeriatrics 1992:203-219.

7. Ventura MM, Bottino CMC. Estudo de confiabilidade da versão em português de uma entrevista estruturada para o diagnóstico de demência. Rev Ass Med Brasil 2001;47:110-116.

8. Folstein MF, Folstein SE, McHugh. Mini-Mental State. J Psychiatr Res 1975;12:189-198.

9. van Swieten JC, Hijdra A, Koudstaal PJ, van Gijn J. Grading white matter lesions on CT and MRI: a simple scale. J Neurol Neurosurg Psychiatry 1990;53:1080-1083.

10. Agresti A. An introduction to categorical data analysis. New York: John Wiley and Sons, Inc, 1996.

11. Conover WJ. Practical nonparametric statistics, 2.Ed. New York: John Wiley \& Sons, Inc., 1980.

12. Steingart A, Hachinski VC, Lau C, et al. Cognitive and neurologic findings in subjects with diffuse white matter lucencies on computed tomographic scan (leuko-araiosis). Arch Neurol 1987;44:32-35.

13. Steingart A, Hachinski VC, Lau C, Fox AJ, Fox H, Lee D, Inzitari D, Merskey $\mathrm{H}$. Cognitive and neurologic findings in demented patients with diffuse white matter lucencies on computed tomographic scan (leukoaraiosis). Arch Neurol 1987;44:36-39.

14. Kluger A, Glanutsos J, Leon MJ, George AE. Significance of age-related white matter lesions. Stroke 1988;19:1054-1055.

15. Hogervorst E, Ribeiro HM, Molyneux A, Budge M, Smith AD. Plasma homocysteine levels, cerebrovascular risk factors, and cerebral white matter changes (leukoaraiosis) in patients with Alzheimer disease. Arch Neurol 2002;59:787-793.

16. Smith EE, Gurol ME, Eng JA, et al. White matter lesions, cognition, and recurrent hemorrhage in lobar intracerebral hemorrhage. Neurology 2004;63:1606-1612. 